Pacific Journal of Mathematics

ADDENDUM TO: "SEQUENCES OF HOMEOMORPHISM 
Addendum to

\title{
SEQUENCES OF HOMEOMORPHISM WHICH CONVERGE TO HOMEOMORPHISMS
}

\author{
Jerome L. PaUL
}

Volume 24 (1968), 143-152

We observe that Theorem 1 remains valid when we omit the relative compactness requirement on the $U_{i}$, and add the hypothesis that $M$ be complete. The proof of the alternative theorem is the same as that of Theorem 1, except that some conclusions which were previously based on relative compactness arguments now follow from completeness.

The alternative Theorem 1 can be used to extend certain results of the paper to the Hilbert space $l_{2}$. In what follows, $M, N$ shall be locally convex topological (real) vector spaces, and $U$ a locally convex subset of $M$ having no isolated points. Given a continuous map $f: U \rightarrow N$, a point $x \in U$ is called a spiral point of $f$ if given any hyperplane (=translate of a codimension one linear subspace) $I I$ containing $f(x)$, and any point $y \neq x$ in $U$, then $f([x, y]) \cap \Pi$ is an infinite set, where $[x, y]$ denotes the (closed) line segment joining $x$ and $y$.

Proposition. Given a continuous map $f: U \rightarrow N$, with $U, N$ as above, the set of nonspiral points of $f$ is dense in $U$.

Proof. Let $x$ and $y$ be any two points such that $[x, y] \subset U$. To prove the proposition, it suffices to show that there is a point $z$ in the open segment $(x, y)$ such that $z$ is not a spiral point of $f$. Note that if $f$ is constant on $[x, y]$, then $[x, y]$ consists entirely of nonspiral points of $f$. Hence, we can assume that there is a point $w \in(x, y)$ such that $f(x) \neq f(w)$. Let $\Pi$ be a hyperplane in $N$ which separates $f(x)$ and $f(w)$. Then there is a (unique) point $z \in(x, w)$ such that $f([x, z]) \cap \Pi=f(z)$, so that $z$ is not a spiral point of $f$, and the proposition is proved.

In spite of the existence of a dense set of nonspiral points for any continuous map $f: U \rightarrow N$, when $M=N=$ the Hilbert space $l_{2}$, we have the following

Theorem. Let $U$ be a locally convex subset, having no isolated points, of the Hilbert space $l_{2}$. Then those topological imbeddings of $U$ into $l_{2}$ which have a dense set (in $U$ ) of spiral points form 
a dense subset, in the fine $C^{0}$ topology, of the set of topological imbeddings of $U$ into $l_{2}$.

The proof of this theorem, which requires the alternative form of Theorem 1, is similar to the proof of Theorem 2 and is therefore omitted. The principal modification needed consists in allowing the maps $F_{c, r, i, j, m}$, (which are now defined on $l_{2}$ in the obvious way using (9)-(9)'"), to act now on the left of the imbeddings via a suitably defined infinite left composition, and where the positive integer $j$ is not subject to the condition $j \leqq n$ of Theorem 2 .

\title{
Correction to
}

\section{DIMENSION THEORY IN POWER SERIES RINGS}

\author{
DAVID E. FIELDS
}

Volume 35 (1970), 601-611

While recently answering a letter of inquiry of $\mathrm{T}$. Wilhelm, I discovered an error in Corollary 4.6. The result, as originally stated, clearly requires that $P \cdot V[[X]] \subset P[[X]]$. However, if $P$ is not branched, it is possible that $P \cdot V[[X]]=P[[X]]$; a counterexample can be obtained from Proposition A.

The following modification of Corollary 4.6 is sufficient for the proof of Theorem 4.7.

COROLLARY 4.6'. Let $V$ be a valuation ring having a proper prime ideal $P$ which is branched. If $P$ is idempotent, then there is a prime ideal $Q$ of $V[[X]]$ which satisfies $P \cdot V[[X]] \subseteq Q \subset P[[X]]$.

Proof. Since $P$ is branched, there is a prime ideal $\bar{P}$ of $V$ with $\bar{P} \subset P$ and such that there are no prime ideals of $V$ properly between $\bar{P}$ and $P[1 ; 173]$. By passing to $V[[X]] / \bar{P}[[X]](\cong(V / \bar{P})[[X]])$, we may assume that $P$ is a minimal prime ideal of $V$.

Since $P$ is idempotent, $P V_{P}$ is idempotent by Lemma 4.1 ; hence $V_{P}$ is a rank one nondiscrete valuation ring. By Theorem 3.4, there is a prime ideal $Q$ of $V_{P}[[X]]$ such that $\left(P V_{P}\right) \cdot V_{P}[[X]] \subseteq Q \subset\left(P V_{P}\right)[[X]]$. But then we see that $Q \subset\left(P V_{P}\right)[[X]]=P[[X]] \subseteq V[[X]]$. Hence $Q \cap V[[X]]=Q$ and $Q$ is a prime ideal of $V[[X]]$ with $P \cdot V[[X]] \subseteq$ $Q \subset P[[X]]$.

The following result is now of interest. 


\section{PACIFIC JOURNAL OF MATHEMATICS}

\section{EDITORS}

RICHARD ARENS (Managing Editor)

University of California

Los Angeles, California 90024

\section{R. A. Beaumont}

University of Washington

Seattle, Washington 98105

\section{J. DuGundJI*}

Department of Mathematics

University of Southern California

Los Angeles, California 90007

D. Gilbarg and J. Milgram

Stanford University

Stanford, California 94305

ASSOCIATE EDITORS
E. F. BECKENBACH
B. H. NeumanN
F. WOLF
K. YoSHIDA

\section{SUPPORTING INSTITUTIONS}

UNIVERSITY OF BRITISH COLUMBIA

CALIFORNIA INSTITUTE OF TECHNOLOGY

UNIVERSITY OF CALIFORNIA

MONTANA STATE UNIVERSITY

UNIVERSITY OF NEVADA

NEW MEXICO STATE UNIVERSITY

OREGON STATE UNIVERSITY

UNIVERSITY OF OREGON

OSAKA UNIVERSITY

\author{
UNIVERSITY OF SOUTHERN CALIFORNIA \\ STANFORD UNIVERSITY \\ UNIVERSITY OF TOKYO \\ UNIVERSITY OF UTAH \\ WASHINGTON STATE UNIVERSITY \\ UNIVERSITY OF WASHINGTON \\ AMERICAN MATHEMATICAL SOCIETY \\ NAVAL WEAPONS CENTER
}

The Supporting Institutions listed above contribute to the cost of publication of this Journal, but they are not owners or publishers and have no responsibility for its content or policies.

Mathematical papers intended for publication in the Pacific Journal of Mathematics should be in typed form or offset-reproduced, (not dittoed), double spaced with large margins. Underline Greek letters in red, German in green, and script in blue. The first paragraph or two must be capable of being used separately as a synopsis of the entire paper. Items of the bibliography should not be cited there unless absolutely necessary, in which case they must be identified by author and Journal, rather than by item number. Manuscripts, in duplicate if possible, may be sent to any one of the four editors. Please classify according to the scheme of Math. Rev. Index to Vol. 39. All other communications to the editors should be addressed to the managing editor, or Elaine Barth, University of California, Los Angeles, California, 90024.

50 reprints are provided free for each article; additional copies may be obtained at cost in multiples of 50 .

The Pacific Journal of Mathematics is issued monthly as of January 1966. Regular subscription rate: $\$ 48.00$ a year (6 Vols., 12 issues). Special rate: $\$ 24.00$ a year to individual members of supporting institutions.

Subscriptions, orders for back numbers, and changes of address should be sent to Pacific Journal of Mathematics, 103 Highland Boulevard, Berkeley, California, 94708.

\section{PUBLISHED BY PACIFIC JOURNAL OF MATHEMATICS, A NON-PROFIT CORPORATION}

Printed at Kokusai Bunken Insatsusha (International Academic Printing Co., Ltd.), 270, 3-chome Totsuka-cho, Shinjuku-ku, Tokyo 160, Japan.

* C. R. DePrima California Institute of Technology, Pasadena, CA 91109, will replace J. Dugundji until August 1974.

Copyright (C) 1973 by

Pacific Journal of Mathematics

All Rights Reserved 


\section{Pacific Journal of Mathematics}

\section{Vol. 49, No. $2 \quad$ June, 1973}

Wm. R. Allaway, On finding the distribution function for an orthogonal polynomial

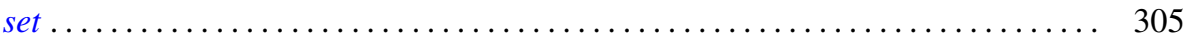

Eric Amar, Sur un théorème de Mooney relatif aux fonctions analytiques bornées... . 311

Robert Morgan Brooks, Analytic structure in the spectrum of a natural system . . . . 315

Bahattin Cengiz, On extremely regular function spaces . . . . . . . . . . . . . . 335

Kwang-nan Chow and Moses Glasner, Atoms on the Royden boundary . . . . . . . . . 339

Paul Frazier Duvall, Jr. and Jim Maxwell, Tame $Z^{2}$-actions on $E^{n} \ldots \ldots \ldots \ldots \ldots . .349$

Allen Roy Freedman, On the additivity theorem for $n$-dimensional asymptotic

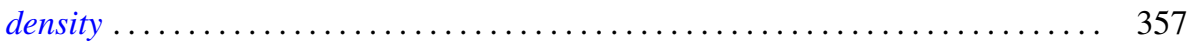

John Griffin and Kelly Denis McKennon, Multipliers and the group $L_{p}$-algebras . . . 365

Charles Lemuel Hagopian, Characterizations of $\lambda$ connected plane continua ....... 371

Jon Craig Helton, Bounds for products of interval functions . . . . . . . . . . . 377

Ikuko Kayashima, On relations between Nörlund and Riesz means . . . . . . . . . . 391

Everett Lee Lady, Slender rings and modules . . . . . . . . . . . . . . . . . . 397

Shozo Matsuura, On the Lu Qi-Keng conjecture and the Bergman representative

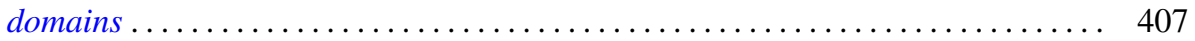

Stephen H. McCleary, The lattice-ordered group of automorphisms of an $\alpha$-set . . . 417

Stephen H. McCleary, o-2-transitive ordered permutation groups .......... 425

Stephen H. McCleary, o-primitive ordered permutation groups. II . . . . . . . . . 431

Richard Rochberg, Almost isometries of Banach spaces and moduli of planar

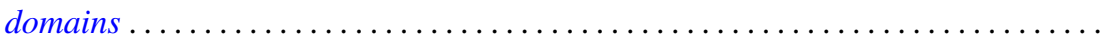

R. F. Rossa, Radical properties involving one-sided ideals . . . . . . . . . . . . . 467

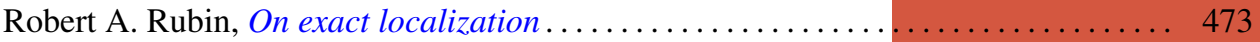

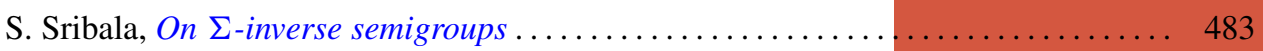

H. M. (Hari Mohan) Srivastava, On the Konhauser sets of biorthogonal polynomials suggested by the Laguerre polynomials ...................... 489

Stuart A. Steinberg, Rings of quotients of rings without nilpotent elements . ...... 493

Daniel Mullane Sunday, The self-equivalences of an $H$-space . . ............ 507

W. J. Thron and Richard Hawks Warren, On the lattice of proximities of $\check{C} e c h$

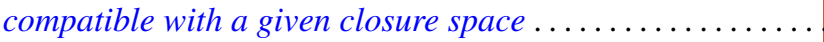

Frank Uhlig, The number of vectors jointly annihilated by two real quadratic forms determines the inertia of matrices in the associated pencil .

Frank Uhlig, On the maximal number of linearly independent real vectors annihilated simultaneously by two real quadratic forms ..............

Frank Uhlig, Definite and semidefinite matrices in a real symmetric matrix pencil . . 561

Arnold Lewis Villone, Self-adjoint extensions of symmetric differential operators . . . 569

Cary Webb, Tensor and direct products . ....................... 579

James Victor Whittaker, On normal subgroups of differentiable

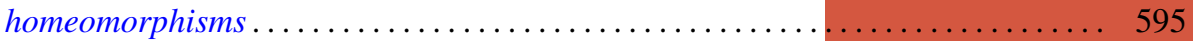

Jerome L. Paul, Addendum to: "Sequences of homeomorphisms which converge to

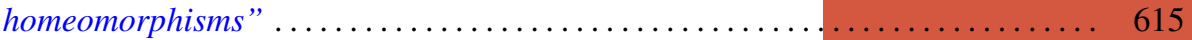

David E. Fields, Correction to: “Dimension theory in power series rings” ........ 616

Peter Michael Curran, Correction to: “Cohomology of finitely presented groups”. . . 617

Billy E. Rhoades, Correction to: “Commutants of some Hausdorff matrices” ...... 617

Charles W. Trigg, Corrections to: "Versum sequences in the binary system” ...... 619 